(8) Partridge, Emest, "Three Wrong Leads in a Search for an Environmental Ethic: Tom Regan on Animal Rights, Inherent Values, and 'Deep Ecology," Ethics \& Animals 5 (1984).

(9) Regan, Tom, The Case for Animal Rights (Berkeley: University of California Press, 1983).

(10) Rodman, John, "The Liberation of Nature?" Inquiry 20 (1977).

(II) Rollin, Bernard, Animal Rights and Human Morality (Buffalo: Prometheus Books, 1981).

(12) Sagoff, Mark, "Animal Liberation and Environmental Ethics, Bad Marriage, quick Divorce," quoted in People, Penguins, and Plastic Trees, eds. VanDeVeer and Pierce (Belmont, CA: Wadsworth, 1986).

(13) Wenz, Peter, "An Ecological Argument for Vegetarianism, " Ethics \& Animals 5 (1984).

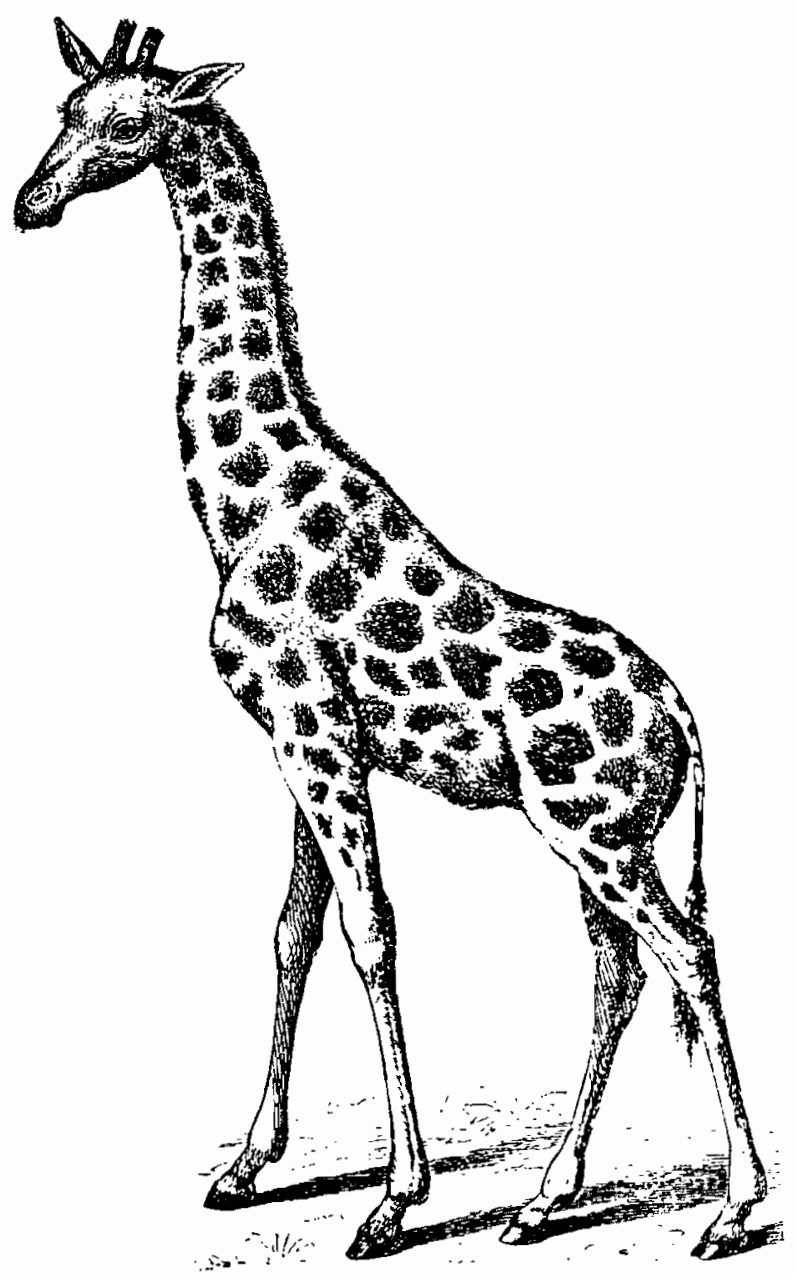

BETWEEN THE SPECIES

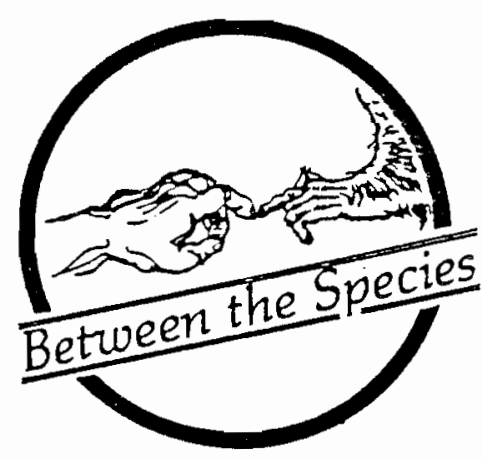

METHODOLOGY IN

APPLIED ENVIRONMENTAL

ETHICS:

Comments on

Dombrowski and Finsen

\author{
ERIC KATZ \\ st. Joseph's College
}

In preparing these remarks, I have assumed that the individual commentators for the papers by Professors Dombrowski and Finsen would focus on specific details of the arguments, leaving me the luxury (and the responsibility) of making some kind of general comparative remarks. So $I$ will begin with some general comments, and then I will try to show how these general remarks can illuninate some specific problems in both papers.

These two papers represent extremely different methodologies of applied ethics. Professor Dombrowski's paper is an example of what I call a "metaphysical" approach to ethical issues. This kind of argument attempts to draw the "proper" ethical conclusions from a specific metaphysical view of

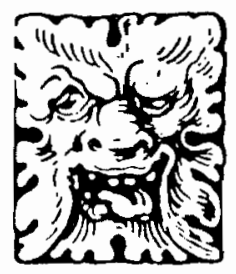

DISCUSSION 
the universe; in Dombrowski's case, it is a view that emphasizes or even sanctifies the "individual" in its various modes as the basis of all ethical thinking. (Obviously, other metaphysical positions might be taken by somebody else.) Professor Finsen's paper, in contrast, seems to avoid wherever possible any metaphysical claims. It is a "nuts and bolts" paper on ethics, almost a practical casuistry of environmental and animal related ethical principles. It attempts to show us that two apparently conflicting ethical principles can operate in rough harmony on the level of practical action. An apparent theoretical incompatibility between animal rightists and environmental holists dissolves in the hands-on work of practical environmental affairs.

Even without looking at these two papers, my initial bias leans me towards the practical "nuts and bolts" approach to applied ethics. After all, applied ethics is meant to be applied; that is, it is meant to help us understand and (it is hoped) solve real problems of human activity in the world. What I want, and what I think we can develop, are practical principles of action that, so to speak, transcend metaphysical positions. If we are required to hold off on practical decisions until the metaphysical decisions

have been made (and agreed upon), then we are in deep trouble: Metaphysical principles are not the kind of things on which people (especially philosophers) usually agree. But sometimes we are lucky when it comes to more mundane practical ethical principles: many of these strike us as eminently reasonable, at face value, despite our uncertainty about or disagreements about, the metaphysical underpinnings of the ethical principles. It is the business of applied ethics, and specifically environmental ethics, to search for these eminently reasonable principles that are obviously certain, as simple and as obvious as the ordinary virtue of truth-telling and promise-keeping.

My initial bias is only confirmed when I look more closely at these two papers. Professor Finsen's work is an attempt to cut through a swamp of controversy regarding the nature of animal rights and environmental ethics, to transcend the theoretical difficulties or incompatibilities of the opposing camps and address the specific issues of practical concern. The real issue here is the balancing of opposing (or at least different) kinds of value, and this is accomplished, it seems to me, in a reasonable manner. Although I am not entirely convinced that the theoretical problems have been solved--that there really is complementarity and not incompatibility--I am able to put aside my theoretical reservations and see how Finsen's view works to alleviate serious practical problems.

Unfortunately, I cannot say the same thing about Professor Dombrowski's paper. Although willing to "bracket" my reservations about his ontological theory of individuals and sentience, I find that when I do, I am not presented with any clear practical principles for action. I cannot find the primary value in Dombrowski's (or is it Hartshorne's?) system. For first, there seems to be a real practical incompatibility between individuals (in the ordinary sense of animals and humans) and the "superanimal" individual, the divine S3. Second, there is an obvious implication that humans themselves are superior to both animals and systens. These two problems leave me without any practical guide to action. When do I value whom is what I want to know. If $\mathrm{s} 3$ is the ultimate entity/

consideration in our obligations, then why aren't our specific (less than ultimate) obligations directed towards systems and collections (species) that will preserve the divine s3? In short, I just don't get it. Dombrowski wants to be able to protect everybody and everything. But this is an ethical position that simply cannot be defended; practically, we cannot do everything, please everybody. Thus--and this is my main point-Dombrowski's position does not seem to be worth the detour into a dubious and controversial ontology of individuals. Even if we buy the Hartshorne/Dombrowski view of reality, we still do not know what to do in the concrete environmental situation. Only Finsen's precise casuistry of environmental and animal conflicts can accomplish that practical task.

More specifically, Dombrowski goes wrong by overemphasizing sentience as the primary fact of individual existence. This forces him to defend the view that all individuals, even atoms, cells, etc., are sentient, and that the world/universe as a whole is sentient in some divine, superpersonal way. Even if we put aside our metaphysical qualms, 
we find that the position has unacceptable ethical results. We are left with a thoroughgoing anthropocentrism: entities are valued and protected to the extent that they resemble human beings or possess mental experiences similar to human beings. This does little good for either animals or the natural environment.

Consider Dombrowski's claim that we must interpret nonhuman nature by analogy with human nature, after all, our own human natures are all that we really know. As a claim about the nature of consciousness, this might be acceptable, but as an ethical claim, I believe it is trivial or dangerous. I could argue that my understanding of other human natures must be based on an analogy with my own white, male, Jewish-American, middle-class experiences, after all, that is all I really experience and know. But if I interpret all experience, all value, from this perspective, I am going to tend to downgrade the experiences of humans different from me, a potentially dangerous view. What really happens is that I attempt to transcend my human individuality and understand other

humans as they are; similarly. I can attempt to transcend my humanity and understand other natural entities as they are. As Aldo Ieopold wrote over forty years ago, the key to environmental ethics is our ability to "think like a mountain." In deciding what is good for the mountain, I think myself in its place. I can do this with other humans; e.g.. I can think like a woman and see that a lifetime sentence of housewifery is a waste of my human potentials. So why can't I do it for other, nonhuman entities?

Also, I think Dombrowski goes wrong when he tries to use aesthetic considerations as the reason to protect holistic systems. This kind of justification will not produce any kind of consensus on problematic environmental issues. The aesthetic beauty of many natural systems (and individuals) is not obvious; indeed, many natural entities and systems are not beautiful, yet we still ought to protect them. Of course, Dombrowski can argue that the divine consciousness 53 considers all natural entities and systems to be beautiful, but we cannot really know that $s 3$ feels that way. Moreover, by claiming that everything is beautiful (for s3) we are really stretching the notion of "beauty" beyond reasonable limits; if everything is beauti- ful, then nothing is.

When we return to Finsen's paper, we find that the problems are on a different level; they involve, as I said earlier, "nuts and bolts" issues. This does not mean that they are not serious; it only means that we can address them, I hope, without an expedition into the realm of metaphysics.

First, I am not sure that Finsen's use of the "rights" view of animal liberation will do the job it is supposed to do, i.e.., alleviate the problems of the Benthamite/sentience view. The rights view, it seems to me, is based on some model of sentience or, what is even worse, a more restrictive criterion such as "subject of a continuous life." So we are still faced with the problem that troubles holistic environmentalists: non-sentient beings do not have rights or moral value.

Second, there is an overemphasis on "stability" as being a desired value for

Robert Nisbet (philosopher) as quoted by John Tierney in "Not to Worry" (Hippocrates, January/February 1988, pp. 28-38) 
environmentalism. After all, a concrete parking lot is relatively stable. of Leopold's three criteria for moral rightness in the environment (beauty, stability, and integrity), only natural integrity seems to make sense. If we consider a forest that is ravaged by a fire caused by a bolt of lightning, we see a simplified system that results from a loss of stability. Moreover, it sustains a major loss of sentient life. Yet, all this is a result of natural processes, and so I see no real loss of value here. I think that this kind of case reflects the compromise criteria that Finsen is trying to develop. The key to understanding natural environmental value is not in stable environments that tend to produce $K$-selectors; the key to understanding environmental value lies in the idea of natural change.

Finally, let me say that both views, animal rights individualism and ecoholism, continue to have problems with seriously endangered species. Proponents of the former cannot say why individual rare animals are more important than plentiful ones, especially when they are ugly. Holists cannot say why non-functioning species (as most rare ones are) are important at all. I have, therefore, developed a theory (or an excuse) based on the idea of reparations. Human society owes compensation to those survivors of any extinction process begun by humans. If this view is correct, then there would be no reason to prevent naturally occurring extinctions, i.e.. extinctions that do not result from human interference in the environment. If the koala bear species eats all the leaves off the eucalyptus trees, thereby dooming both the tree species and itself, then it is simply too bad for the koala bear. They will be extinct, and humanity does not have to feel the least bit guilty.

In conclusion, let me repeat my claim that we are presented here with two different methodologies of applied ethics. The most important issue thus facing us is which approach we will take as we try to solve ethical problems regarding animals and the environment. I vote for examining the resolution of problems in the concrete situation and for postponing metaphysical speculations, however interesting they may be, because they rarely lead to pragmatic solutions.

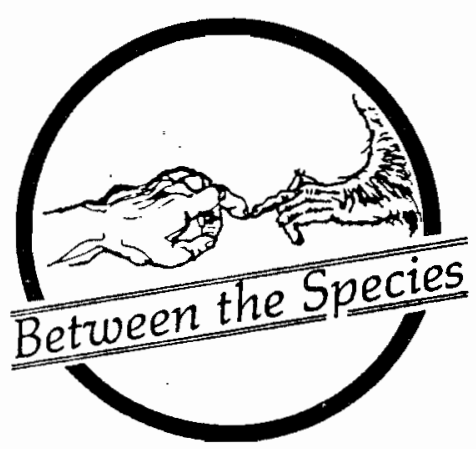

\section{ANIMAL RIGHTS}

AND ECOHOLISM

\section{ARE NOT COMPATIBLE}

\author{
SIDNEY GENDIN \\ Eastern Michigan University
}

In her admirable paper, Professor Finsen succeeds in clarifying the views of some of the leading ecoholists, and she also succeeds in showing that their views are not terribly far from those of the animal rights people. Nevertheless, there are important differences between the philosophy of ecoholism and that of animal rights that cannot be minimized. Professor Finsen is too ambitious in supposing that she can supply a theoretical reconciliation of the two positions.

I take it that the essence of Professor Finsen's paper is that those she calls ecoholists-for example, Rodman and Leopold-love not any old biotic environment but those that show "integrity, stability and beauty." These are precisely the environments that are particularly kind to the organisms that animal rights proponents favor. As she put it, the ecoholist "values the very systems which give rise to the sentient beings valued by

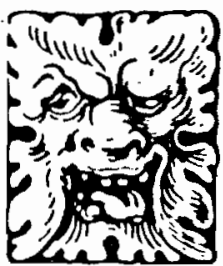

DISCUSSION 